\title{
FORECASTING OF INDONESIA SEAWEED EXPORT: A COMPARISON OF FUZZY TIME SERIES WITH AND WITHOUT MARKOV CHAIN
}

\author{
Andi Sri Bintang ${ }^{1}$, Wen-Chi Huang ${ }^{2}$, Rosihan Asmara ${ }^{3}$ \\ ${ }^{1}$ Double Degree Program in Faculty Agriculture, Brawijaya University, Indonesia and National Pingtung \\ University Science and Technology, Taiwan \\ ${ }^{2}$ National Pingtung University Science and Technology, Taiwan \\ ${ }^{3}$ Faculty Agriculture Brawijaya University, Indonesia \\ *corresponding author: andisribintang15@gmail.com
}

\begin{abstract}
This study compared Fuzzy Time Series with and without Markov Chain Method for forecasting Indonesian seaweed export in particular; it analyzed the forecasting ability of the models and the effects of different lengths of interval and increment information on the forecasting error of models. The secondary data between 1989 and 2018 were collected from Bureau Central Statistic (BPS), UN Comtrade, Ministry Marine and Fisheries (KKP). The results indicate that Fuzzy Time Series with and without Markov Chain method performs better in the forecasting ability in short-term period prediction and the values of Mean Absolute Percentage Error (MAPE) and Mean Square Error (MSE) tends to be smaller than the Fuzzy Time Series without Markov Chain.
\end{abstract}

Keywords: Seaweed export, Forecasting, Fuzzy Time Series, Markov Chain

http://dx.doi.org/10.21776/ub.agrise.2019.019.3.4

Received 09 July 2019

Accepted 30 July 2019

Available online 25 August 2019

\section{INTRODUCTION}

Seaweed is one of the main commodities of fishery products. In Indonesia This commodity has great potential to be developed because it is supported by increasing market demand. Indonesian seaweed in international trade is the largest and dominates the world market share (Ministry Marine and Fisheries, 2019) Seaweed products exported by Indonesia are dried seaweed, gelatin and carrageenan which experience fluctuations every year. The biggest seaweed export is dried seaweed Marketing of dried seaweed from farmer to exporter/ factories is carried out through four channels, namely: First, Farmer selling of dried seaweed to wholesaler, and wholesaler directly to exporter. Second, Farmer selling of dried seaweed to wholesaler, and wholesaler directly to factories. Third, Farmer selling to retail and from retail to wholesaler that they had relationship with exporter Fourth, Farmer selling to retail and then from retail selling to domestic market. From these four channels, around $50 \%$ that farmer normally used first channel (Assosiation Seaweed Indonesia, 2019).

Indonesia in second rank after Korea to export fresh, chilled, and dried seaweed. It means that Indonesia is one of the main suppliers of dried seaweed in the world. The importance of seaweed commodities for the Indonesian people as one of the main sources of income. The upstream seaweed sector contributed to foreign exchange reaching US $\$ 160,408,809$.

The choice of forecasting method depends on the cost of preparing forecasting and benefit resulting from its use, the time period in making a decision, forecasting period, desired level of accuracy, data quality, and availability, and the level of complexity of the relationships that will be predicted (Brockwel, 2002). The fuzzy time series 
model is applied as a valid approach for forecasting the future value in a situation where neither a trend is viewed nor a pattern in variations of time series is visualized and, moreover, the information is incomplete and ambiguous.

Markov process is a stochastic model that has the Markov property. It can be used to model a random system. Markov decision processes (MDPs) give a mathematical framework for modeling the situations where outcomes are partly random and partly under the control of a decision maker (Uzun, 2017). Markov Chain Analysis is a method that studies the properties of a variable in the present which is based on traits in the past in an effort to assess these traits in the future (Budiharto, 2014). To learn more about the benefits of the relationship of Markov processes with the FTS model that is by following the rules of the Markov FTS model (Central Statistics Agency, 2019). In his research Tsaur combines fuzzy time series methods with markov chains, the merger aims to obtain the greatest probability using a transition probability matrix. The results of the study show that the fuzzy time series markov chain method provides a fairly good accuracy compared to the fuzzy time series method.

The problems is decreasing export dried seaweed, this study aims to examine the forecast of seaweed export, compared Fuzzy Time Series with and without Markov Chain to know the best model, At the same time, the study will also investigate the effects of interval length and information on models' forecasting ability.

\section{RESEARCH METHODS}

The limitation in this study is focus for dried seaweed (HS 12122190) between 1989 and 2018, with a unit of volume kilograms (Kg). Used secondary export data, were collected from BPS, KKP, UN Comtrade, Trade Map, and other relevant ministries. Data wed analyzed using Fuzzy Time Series with and without Markov Chain.

\section{Time Series Analysis}

A key role in time series analysis is played by processes, or some of them, do not vary with time. If we wish to make predictions, then we must assume that something does not vary with time. In extrapolating deterministic functions, it is a common practice to assume that either the function itself or one of its derivatives is constant. The assumption of a constant first derivative to linear extrapolation as a means of prediction. In our goal is to predict a series that typically is not deterministic but contains a random component. If the random component is stationary, then we can develop powerful techniques to forecast future values (Brockwel, 2002).

The main purpose of time series analysis is to study and understand how the characteristic under study evolves with respect to time so that the underlying probabilistic mechanism generating the time series is determined with reliable accuracy, once this is done, one can try to predict the future behavior of the characteristic. The main objective in analyzing time series is to understand, interpret and evaluate changes in the phenomena in the hope of more correctly anticipating the course of future events. A good understanding of the mechanism generating the series may also help us to control the phenomena involved in the generating mechanism and thereby control the future behavior of the process (Arumugam, 2015).

\section{Fuzzy Set and Forecasting}

The fuzzy sets theory can be defined as a mathematical formalization that enables us to eliminate indefiniteness and deal with incomplete, inaccurate information of both qualitative and quantitative by nature (Arumugam, 2015).

The fuzzy set theory was introduced by Zadeh (1996). Zadeh released the theory of classical sets into fuzzy sets so that the classic set (crisp set) is a special event of a fuzzy set. Then Zadeh approved the association to escape by using the membership function (membership function) which was valued at closed intervals $[0,1]$. Being able to help in a set of passes is not something that is expressed again, something that is degree or continuous gradation.

\section{Fuzzy Time Series (FTS)}

Fuzzy Time Series (FTS) is a forecasting data method that uses the concept of fuzzy set as the basis of calculations. The forecasting system with this method works by returning patterns from actual data and then used to project future data. The process also does not require a learning system from a complex system, as is the case with genetic algorithms and neural networks so that it is easy to use and develop (Ruey, 2016). Fuzzy Time Series (FTS) has terms that are published, namely Fuzzy Logic Relations (FLR) and Fuzzy Logic Relations 
Group (FLRG). Fuzzy Logic Relations (FLR) is a fuzzy logic that has a relationship between the series of associations that have been set in the previous data and continued. Then FLRG is only the same as FLR, but only what is determined is the group making from FLR which is the same as the weighted group.

Song and Chissom first proposed the definitions of fuzzy time series. Let $U$ be the universe of discourse with $U=\{u 1, u 2, \ldots$, un $\}$ in which a fuzzy set $A i(i=1,2, \ldots, n)$ is defined as follows:

$$
A_{\mathrm{i}}=f_{\mathrm{Ai}}\left(u_{\mathrm{k}}\right) / u_{\mathrm{k}}+f_{\mathrm{Ai}}\left(u_{\mathrm{k}}\right) / u_{\mathrm{k}}+\cdots+f_{\mathrm{Ai}}\left(u_{\mathrm{k}}\right) /
$$
$u_{\mathrm{k}}$

Where, $f_{\mathrm{Ai}}$ is the membership function of the fuzzy set $A i, u k$ is an element of fuzzy set $A i$, and $f$ ${ }_{A i}(u k)$ is the membership degree of $u k$ belonging to $A i, k=1,2, \ldots n$.

Step 1. Define universe of discourse and the intervals. When defining the universe of discourse, the minimum data and the maximum data of given actual data are obtained as $D_{\min }$ and $D_{\max }$, respectively. On the basis of $D_{\min }$ and $D_{\max }$, we can define the universal discourse as:

$$
U=\left[D_{\min }-D_{1}, D_{\max }+D_{2}\right]
$$

Where, $D_{1}$ and $D_{2}$ are the positive number that determines the effective long interval is the average based Fuzzy Time Series model (Xihao, 2009).

Step 2. Divide the intervals. Partition universal discourse $U$ into several equal intervals. Let the universal discourse $U$ be partitioned into $n$ equal intervals; the difference between two successive intervals can be defined as $\ell$ as follows:

$$
\ell=\left[\left(D_{\max }+D 2\right)-\left(D_{\min }-D 1\right)\right] / n
$$

Step 3. Classify the fuzzy sets. There is no restriction on determining how many linguistic variables can be fuzzy sets. Thus, the "enrollment" can be described by the fuzzy sets of $A 1=$ (not many), $A 2=$ (not too many), $A 3=$ (many),$A 4=$ (many many), $A 5=$ (very many), $A 6=($ too many $)$. For simplicity, each fuzzy set $A i(i=1,2, \ldots 6)$ is defined on 6 intervals, which are $\mathrm{u} 1=[d 1, d 2], u 2$ $=[d 2, d 3], u 3=[d 3, d 4], u 4=[d 4, d 5], u 5=[d 5$, $d 6], u 6=[d 6, d 7]$; thus, the fuzzy sets $A 1, A 2, \ldots$, $A 6$ are defined as follows:

$A 1=\{1 / u 1,0.5 / u 2,0 / u 3,0 / u 4,0 / u 5,0 / u 6\}$, $A 2=\{0.5 / u 1,1 / u 2,0.5 / u 3,0 / u 4,0 / u 5,0 / u 6\}$, $A 3=\{0 / u 1,0.5 / u 2,1 / u 3,0.5 / u 4,0 / u 5,0 / u 6\}$,
$A 4=\{0 / u 1,0 / u 2,0.5 / u 3,1 / u 4,0.5 / u 5,0 / u 6\}$, $A 5=\{0 / u 1,0 / u 2,0 / u 3,0.5 / u 4,1 / u 5,0.5 / u 6\}$, $A 6=\{0 / u 1,0 / u 2,0 / u 3,0 / u 4,0.5 / u 5,1 / u 6\}$,

Step 4. Fuzzy the data. Fuzzy the actual data. This step aims to find an equivalent fuzzy set for each input data. The used method is to define a cut set for each $A i(i=1 \ldots 6)$. If the collected time series data belongs to an interval $u_{\mathrm{i}}$, then it is fuzzy to the fuzzy set $A i$.

Step 5. Create the fuzzy relationships. the fuzzy logical relationship group can be easily obtained. If there are fuzzy logical relationships obtained from state $A 2$, then a transition is made to another state $A j, j=1,2 \ldots, n$, as $A 2 \rightarrow A 3, A 2 \rightarrow$ $A 2, \ldots, A 2 \rightarrow A 1$; hence, the fuzzy logical relationships are grouped into a fuzzy logical relationship group [4] as $A 2 \rightarrow A 1, A 2, A 3$

Step 6. Defuzzy the forecasting results. Calculate the forecasted outputs. If $F(t-1)=A j$, the forecasting of $F(t)$ is conducted on the basis of the following rules.

Rule 1: If the fuzzy logical relationship group of $A j$ is empty (i.e., $A j \rightarrow \varnothing$ ), then the forecasting of $F(t)$ is $\mathrm{mj}$, which is the midpoint of interval $u j$ : $F(t)=m j$.

Rule 2: If the fuzzy logical relationship group of $A j$ is one-to-one (i.e., $A j \rightarrow A k, j, k=1,2 \ldots, 6$ ), then the forecasting of $F(t)$ is $\mathrm{mk}$, the midpoint of interval $u k$ :

$F(t)=m k$.

Rule 3: If the fuzzy logical relationship group of $A j$ is one-to-many (i.e., $A j \rightarrow A 1, A 3, A 5, j=1$, $2, \ldots, 6)$, then the forecasting of $F(t)$ is equal to the arithmetic average of $m 1, m 3, m 5$, the midpoint of $u 1, u 3, u 5$ :

$$
F(t)=(m 1+m 2+m j) / n
$$

\section{Fuzzy Time Series with Markov-Chain (FTS- MC)}

The Markov Chain (Markov Chain) was first developed by Russian experts named A. A. Markov in 1906. Conceptually the Markov chain can be illustrated by assuming $\{X n, \mathrm{n}=0,1,2, \ldots\}$ as a finite stochastic process or the probability value that can be calculated (Hikmah, 2015). Fuzzy time series markov chain is a new concept that was first proposed by Tsaur, in his research to analyze the accuracy of the prediction of the exchange rate of Taiwan currency with US dollars (4)aur, 2012). In his research Tsaur combines fuzzy time series methods with markov chains, the merger aims to 
obtain the greatest probability using a matrix transition probability. The forecasting procedure from Step 1 to Step 4 is the same as the conventional fuzzy time series model, and some descriptions of my proposed method are defined from Step 5 to Step 7 below.

Step 5. Calculate the forecasted outputs. For a time series data, using the fuzzy logical relationship group, we can induce some regular information and try to find out what is the probability for the next state. The transition probability of state is written as:

$$
P i j=(M i j) / M i, i, j=1,2, \ldots, n
$$

where $P i j$ is the probability of transition from state $A i$ to $A j$ by one step, $M i j$ is the transition times from state $A i$ to $A j$ by one step, and $\mathrm{Mi}$ is the amount of data belonging to the $A i$ state. Then, the transition probability matrix $\mathrm{R}$ of the state can be written as:

$$
\left[\begin{array}{cccc}
P 11 & P 12 & \cdots & P 1 n \\
P 21 & P 22 & \cdots & P 2 n \\
\vdots & \vdots & \therefore & \vdots \\
P n 1 & P n 2 & \cdots & P n n
\end{array}\right]
$$

For the matrix R, some definitions are described as follows:

- $\quad$ If $P i j \geq 0$, then state $A j$ is accessible from state Ai.

- If states $A i$ and $A j$ are accessible to each other, then $A i$ communicates with $A j$

Rule 1: If the fuzzy logical relationship group of $A i$ is one-to-one (i.e., $A i \rightarrow A k$, with $P i k=1$ and $P i j=$ $0, j 6=k$ ), then the forecasting of $F(t)$ is $m k$, the midpoint of $u k$, according to the equation: $F(t)=$ $m k P i \mathrm{k}=m k$.

Rule 2: If the fuzzy logical relationship group of $A j$ is one-to-many (i.e., $A j \rightarrow A 1, A 2, \ldots, A n, j=$ $1,2, \ldots, n)$, when collected data $Y(t-1)$ at time $t-1$ is in the state $A j$, then the forecasting of $F(t)$ is equal as :

$F(t)=m 1+P j 1+m 2 P j 2+\ldots+m j-1 P j(j-1)+$ $Y(t-1) P j j+m j+1 P j(j+1)+\ldots+m n P j n$, where $m l$, $m 2, \ldots, m j-1, m j+1, \ldots, m n$ are the midpoint of $u 1$, $u 2, \ldots, u j-1, u j+1, \ldots, u n$, and $m j$ is substituted for $Y(t$ - 1) in order to take more information from the state $A j$ at time $t-1$.

Step 6. Adjust the tendency of the forecasting values. For any time series experiment, a large sample size is always necessary. Therefore, under a smaller sample size when modeling a fuzzy time series -Markov chain model, the derived Markov chain matrix is usually biased, and some adjustments for the forecasting values are suggested to revise the forecasting error. First, in a fuzzy logical relationship group where $A i$ communicates with $A i$ and is one-to-many, if a larger state $A j$ is accessible from state $A i, i, j=1$, $2 \ldots, n$, then the forecasting value for $A j$ is usually underestimated because the lower state values are used for forecasting the value of $A j$.

Rule 1. If state $A i$ communicates with $A i$, starting in state $A i$ at time $t-1$ as $F(t-1)=A i$, and makes an increasing transition into state $A j$ at time $t,(i<j)$, then the adjusting trend value $D t$ is defined as $D t 1$ $=(\ell / 2)$.

Rule 2. If state $A i$ communicates with $A i$, starting in state $A i$ at time $t-1$ as $F(t-1)=A i$, and makes an increasing transition into state $A \mathrm{j}$ at time $\mathrm{t},(\mathrm{i}<\mathrm{j})$, then the adjusting trend value $D t$ is defined as $D t 1$ $=-(\ell / 2)$.

Rule 3. If the current state is in state $A i$ at time $t-1$ as $F(t-1)=A i$, and makes a jump-forward transition into state $A i+s$ at time $t,(1 \leq s \leq n-i)$, then the adjusting trend value $D t$ is defined as $D t 2$ $=(\ell / 2) s,(1 \leq s \leq n-i)$, where is the length that the universal discourse $U$ must be partitioned into as $n$ equal intervals.

Rule 4. If the process is defined to be in state $A i$ at time $t-1$ as $F(t-1)=A i$, then makes a jumpbackward transition into state $A i-v$ at time $t, l \leq v$ $\leq i$, the adjusting trend value $D t$ is defined as $D t 2=$ $-(\ell / 2) v, 1 \leq v \leq I)$.

Step 7. Obtain adjusted forecasting result. If the fuzzy logical relationship group of $A i$ is one-tomany, and state $A i+1$ is accessible from state $A i$ in which state $A i$ communicates with $A i$, then adjusted forecasting result $F \ell(t)$ can be obtained as $F \ell(t)=F(t)+D t 1+D t 2=F(t)+(\ell / 2)+(\ell / 2)$. If the fuzzy logical relationship group of $A i$ is oneto-many, and state $A i+1$ is accessible from state $A i$ but state $A i$ does not communicate with $A i$, then adjusted forecasting result $F \ell(t)$ can be obtained as $F \ell(t)=F(t)+D t 2=F(t)+(\ell / 2)$. If the fuzzy logical relationship group of $A i$ is one-to-many, and state $A i-2$ is accessible from state $A i$ but state $A i$ does not communicate with $A i$, then adjusted forecasting result $F \ell(t)$ can be obtained as $F \ell(t)$ $=F(t)-D t 2=F(t)-(\ell / 2) \times 2=F(t)-\ell$ 
When $v$ is the jump step, the general form for forecasting result $F \ell(t)$ can be obtained as

$$
\begin{gathered}
F \ell(t)=F(t) \pm D t 1 \pm D t 2=F(t) \pm(\ell / 2) \pm(\ell \\
/ 2) v
\end{gathered}
$$

Finally, the Mean Absolute Percentages Error (MAPE) is used to measure the accuracy as a percentage as follows.

$$
M A P E=\frac{1}{n} \sum_{t=1}^{n} \frac{\left\lfloor Y(t)-F^{\prime}(t)\right\rfloor}{Y(t)} \times 100 \%
$$

In addition there are other methods, namely the Mean Square Error (MSE) method. Following is the formula for MSE:

$$
M S E=\frac{1}{n} \sum_{t=1}^{n}\left(Y(t)-F^{\prime}(t)\right) 2
$$

\section{RESULTS AND DISCUSSION}

In this study the Fuzzy Time Series-Markov Chain (FTS-MC) model was applied to dried seaweed (HS 121220) export data from 1989-2018 obtained from the Central Statistics Agency (BPS). Data are presented in the Table 1.

Table 1. Seaweed Export Data 1989- 2018

\begin{tabular}{cccccc}
\hline Time & Period & Netweight $(\mathrm{Kg})$ & Time & Period & Netweight $(\mathrm{Kg})$ \\
\hline 1 & 1989 & $12,085,220$ & 16 & 2004 & $51,010,828$ \\
2 & 1990 & $11,787,614$ & 17 & 2005 & $69,264,256$ \\
3 & 1991 & $11,304,509$ & 18 & 2006 & $95,588,055$ \\
4 & 1992 & $12,046,665$ & 19 & 2007 & $94,073,398$ \\
5 & 1993 & $16,561,598$ & 20 & 2008 & $99,948,576$ \\
6 & 1994 & $18,688,648$ & 21 & 2009 & $94,002,964$ \\
7 & 1995 & $24,957,652$ & 22 & 2010 & $123,074,961$ \\
8 & 1996 & $22,310,072$ & 23 & 2011 & $159,075,454$ \\
9 & 1997 & $12,698,516$ & 24 & 2012 & $81,462,769$ \\
10 & 1998 & $5,213,188$ & 25 & 2013 & $74,563,691$ \\
11 & 1999 & $25,084,399$ & 26 & 2014 & $81,946,882$ \\
12 & 2000 & $23,073,441$ & 27 & 2015 & $49,914,826$ \\
13 & 2001 & $27,874,058$ & 28 & 2016 & $81,399,417$ \\
14 & 2002 & $28,559,855$ & 29 & 2017 & $38,019,409$ \\
15 & 2003 & $40,162,037$ & 30 & 2018 & $12,056,862$ \\
\hline
\end{tabular}

Source: BPS, various years from 1989 to 2018

\section{Fuzzy Time Series with and without Markov Chain}

\section{Data Preparation}

Step 1. Define universe of discourse $U$ and partition it into several equal-length intervals. The collected data is shown in the table 1; we have the enrollments of the $U$ from 1989 to 2018 with $D_{\text {min }}$ $=5213188$ and $D_{\max }=159075454$. I choose $D_{1}=21318$ and $D_{2}=75454$. From equation (2) the results are equal to $U=[5191870 ; 159150908]$

Step 2. Define fuzzy sets on the universe $U$. The step has the same defined fuzzy sets. Dividing (partitioning) the $U$ part into several parts, the number of intervals $(n)$ is 6 intervals. Then the set $U$ which has been predetermined, divided into 6 equal length intervals to determine linguistic values and fuzzy data. Using equations (3) the $l$ value is $25,659,839,67$

Step 3. Classify the fuzzy sets. There is no restriction on determining how many linguistic variables can be fuzzy sets. There are 6 intervals that can be made based on the number of intervals

u1, u2, u3, u4, u5, u6,

$u l=[5,213,188 ; 30,873,027.7]$,

$u 2=[30,873,027.67 ; 56,532,867.30]$,

$u 3=[56,532,867.33 ; 82,192,707]$,

$u 4=[82,192,707 ; 107,852,547]$

$u 5=[107,852,546.70 ; 133,512,386]$,

$u 6=[133,512,386.30 ; 159,172,226]$.

With mean intervals 
$m l(18,043,107.83)$,

$m 3(69,362,787.17)$,

$m 5(120,682,466.50)$, $m 2(43,702,947.50)$, $m 4(95,022,626.83)$, $m 6(146,342,306.20)$.
Step 4. Fuzzy the actual data. The forecasted values of Indonesia Seaweed show in table 2 and each fuzzy set has 6 elements.

Table 2. The forecasted values of Indonesia Seaweed

\begin{tabular}{cccccccc}
\hline Time & Year & Actual data & Fuzzy Data & Time & Year & Actual data & Fuzzy Data \\
\hline 1 & 1989 & $12,085,220$ & A1 & 16 & 2004 & $51,010,828$ & A2 \\
2 & 1990 & $11,787,614$ & A1 & 17 & 2005 & $69,264,256$ & A3 \\
3 & 1991 & $11,304,509$ & A1 & 18 & 2006 & $95,588,055$ & A4 \\
4 & 1992 & $12,046,665$ & A1 & 19 & 2007 & $94,073,398$ & A4 \\
5 & 1993 & $16,561,598$ & A1 & 20 & 2008 & $99,948,576$ & A4 \\
6 & 1994 & $18,688,648$ & A1 & 21 & 2009 & $94,002,964$ & A4 \\
7 & 1995 & $24,957,652$ & A1 & 22 & 2010 & $123,074,961$ & A5 \\
8 & 1996 & $22,310,072$ & A1 & 23 & 2011 & $159,075,454$ & A6 \\
9 & 1997 & $12,698,516$ & A1 & 24 & 2012 & $81,462,769$ & A3 \\
10 & 1998 & $5,213,188$ & A1 & 25 & 2013 & $74,563,691$ & A3 \\
11 & 1999 & $25,084,399$ & A1 & 26 & 2014 & $81,946,882$ & A3 \\
12 & 2000 & $23,073,441$ & A1 & 27 & 2015 & $49,914,826$ & A2 \\
13 & 2001 & $27,874,058$ & A1 & 28 & 2016 & $81,399,417$ & A3 \\
14 & 2002 & $28,559,855$ & A1 & 29 & 2017 & $38,019,409$ & A2 \\
15 & 2003 & $40,162,037$ & A2 & 30 & 2018 & $12,056,862$ & A1 \\
\hline
\end{tabular}

Step 5. Determine the fuzzy logical relationship group. The fuzzy logical relationship group is obtained as shown in Table 3.

Table 3. Fuzzy logical relationship group (FLRG)

\begin{tabular}{cc}
\hline Current State & Next State \\
\hline A1 & $13(A 1), 1(A 2)$ \\
A2 & $1(\mathrm{~A} 1), 1(\mathrm{~A} 2), 3(\mathrm{~A} 3)$ \\
A3 & $3(\mathrm{~A} 3), 1(\mathrm{~A} 4)$ \\
A4 & $4(\mathrm{~A} 4)$ \\
A5 & $1(\mathrm{~A} 6)$ \\
A6 & $1(\mathrm{~A} 3)$ \\
\hline
\end{tabular}

Step 6. Adjust the tendency of the forecasting values. Transition process shows the relationship between states where a one-way arrow indicates that the state transitions from one state to the next but does not apply otherwise, these states are $A 2$, A5 and A6. Meanwhile, the two-way arrow indicates that the state transitions from one state to the next and applies the opposite relationship between these states, these states are $A 1$ and $A 2, A 3$ and $A 4$. The arrow that indicates towards itself means that the state is transitioning to itself, these states are $A 1, A 2, A 3$, and $A 4$.

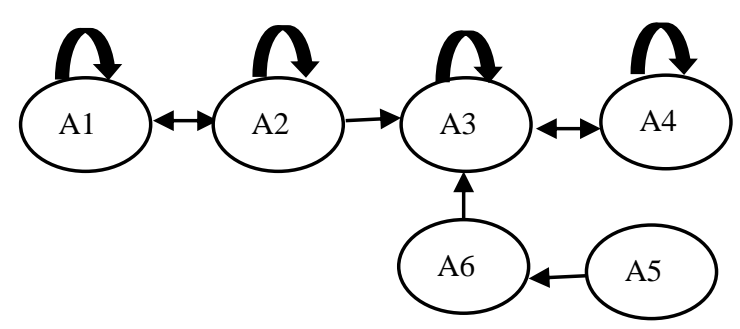

Figure 1. Transition process for Indonesia Seaweed Export forecasting

Step 7. The adjusted values are obtained as in the fourth column of table 4.

Step 8. Obtain adjusted forecasting values. The adjusted forecasting values are obtained in the last column of Table 4 . The adjusted forecasting value for 1974 is $F^{\prime}(2003)=F^{(2003)+}$ $12,829,919.83=42,471,424.30$. 
Table 4. Forecasting of Indonesian Seaweed Export

\begin{tabular}{|c|c|c|c|c|}
\hline Year & Actual data & Forecasted Value & Adjusted Value & Adjusted Forecasting value \\
\hline 1989 & $12,085.220$ & 0 & 0 & 0 \\
\hline 1990 & $11,787.614$ & $14,343,629.11$ & 0 & $14,343,629.11$ \\
\hline 1991 & $11,304.509$ & $14,067,280.68$ & 0 & $14,067,280.68$ \\
\hline 1992 & $12,046.665$ & $13,618,683.18$ & 0 & $13,618,683.18$ \\
\hline 1993 & $16,561.598$ & $14,307,828.04$ & 0 & $14,307,828.04$ \\
\hline 1994 & $18,688.648$ & $18,500,265.82$ & 0 & $18,500,265.82$ \\
\hline 1995 & $24,957.652$ & $20,475,383.68$ & 0 & $20,475,383.68$ \\
\hline 1996 & 22.310 .072 & $26,296,601.68$ & 0 & $26,296,601.68$ \\
\hline 1997 & $12,698.516$ & $23,838,134.54$ & 0 & $23,838,134.54$ \\
\hline 1998 & $5,213.188$ & $14,913,118.25$ & 0 & $14,913,118.25$ \\
\hline 1999 & $25,084.399$ & $7,962,456.53$ & 0 & $7,962,456.53$ \\
\hline 2000 & $23,073.441$ & $26,414,295.32$ & 0 & $26,414,295.32$ \\
\hline 2001 & $27,874.058$ & $24,546,977.18$ & 0 & $24,546,977.18$ \\
\hline 2002 & $28,559.855$ & $29,004,692.96$ & 0 & $29,004,692.96$ \\
\hline 2003 & $40,162.037$ & $29,641,504.46$ & $12,829,919.83$ & $42,471,424.30$ \\
\hline 2004 & $51,010.828$ & $53,258,701.27$ & 0 & $53,258,701.27$ \\
\hline 2005 & $69,264.256$ & $55,428,459.47$ & $12,829,919.83$ & $68,258,379.30$ \\
\hline 2006 & $95,588.055$ & $75,703,848.71$ & $12,829,919.83$ & $88,533,768.54$ \\
\hline 2007 & $94,073.398$ & $95,588,055.00$ & 0 & $95,588,055.00$ \\
\hline 2008 & $99,948.576$ & $94,073,398.00$ & 0 & $94,073,398.00$ \\
\hline 2009 & $94,002.964$ & $99,948,576.00$ & 0 & $99,948,576.00$ \\
\hline 2010 & $123,074.961$ & $94,002,964.00$ & 0 & $94,002,964.00$ \\
\hline 2011 & $159,075.454$ & $120,682,466.5$ & $12,829,919.83$ & $133,512,386.30$ \\
\hline 2012 & $81,462.769$ & $69,362,787.17$ & $-38,489,759.50$ & $30,873,027.67$ \\
\hline 2013 & $74,563.691$ & $84,852,733.46$ & 0 & $84,852,733.46$ \\
\hline 2014 & $81,946.882$ & $79,678,424.96$ & 0 & $79,678,424.96$ \\
\hline 2015 & $49,914.826$ & $85,215,818.21$ & 0 & $85,215,818.21$ \\
\hline 2016 & $81,399.417$ & $55,209,259.07$ & $12,829,919.83$ & $68,039,178.9$ \\
\hline 2017 & $38,019.409$ & $61,506,177.27$ & $12,829,919.83$ & $743,36,097.1$ \\
\hline 2018 & $12,056.862$ & $52,830,175.67$ & $-12,829,919.83$ & $40,000,255.83$ \\
\hline
\end{tabular}

\section{Comparison of Fuzzy Time Series and Markov Chain}

Forecasting using Fuzzy Time Series (FTS) is done to get the appropriate comparison model. The difference between Fuzzy Time Series-Markov Chain (FTS-MC) and FTS is the forecasting step. Forecast calculations using FTS use equations (Rule1), (Rule2), and (Rule3). For example, for forecasting in 1990 the data seen is the previous year's data, namely 1989 where the state transitioned from $A l$ to $A l$, the forecasting calculation uses equation (7) because of Fuzzy
Logical Relationship Group (FLRG) from $A l$ is one to $A l$, namely:

$$
\begin{aligned}
F(1990) & =m 1+m 2 / \mathrm{n} \\
& =18,043,107.83+43,702,947.50 / 6 \\
& =25,326,932.42
\end{aligned}
$$




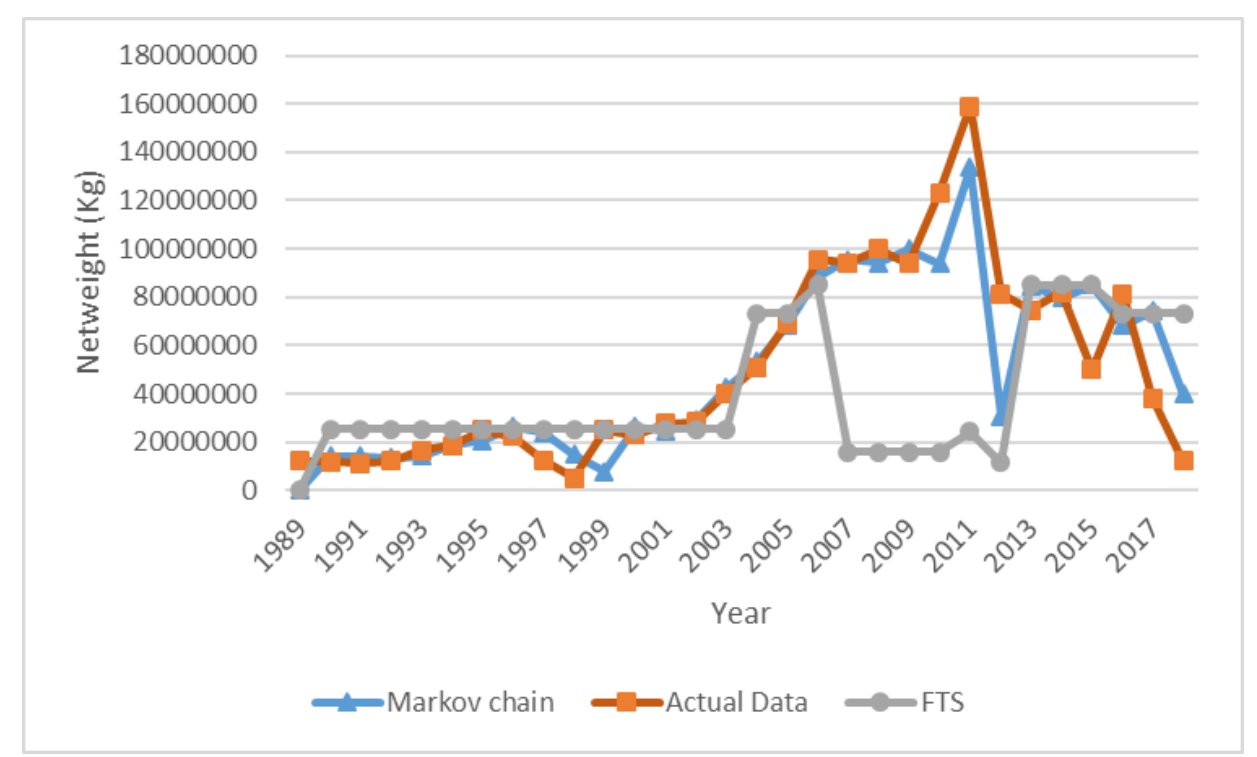

Figure 2. The comparisons in Indonesia Seaweed Export

Following the above steps, a comparison among actual enrollment, some revised fuzzy time series methods, and the proposed model are shown in figure 2. It is obvious that these revised methods also have plots similar to the proposed model. Therefore, an estimated error method, Mean Absolute Percentage Error (MAPE), and Mean Square Error (MSE) is used for comparing the methods as shown in table 5.
It is obvious that the forecasting error of Mean Absolute Percentage Error (MAPE) and Mean Square Error (MSE) Fuzzy Markov Chain in regard to the proposed method is $1.1 \%$ and 0.26 . That the forecasting error of Mean Absolute Percentage Error (MAPE) and Mean Square Error (MSE) Fuzzy Time Series proposed method is $2.0 \%$ and 0,8 which is better than that of the other methods. Using the fuzzy time seriesMarkov model a better forecasting result can be derived.

Table 5. Comparison Fuzzy Time Series Markov Chain and Fuzzy Time Series

\begin{tabular}{l|c|c}
\hline & $\begin{array}{c}\text { Fuzzy Time Series Markov-Chain } \\
\text { (FTS-MC) }\end{array}$ & Fuzzy Time Series (FTS) \\
\hline Mean Absolute Percentage Error (MAPE) & $1.1 \%$ & $2.0 \%$ \\
\hline Mean Square Error (MSE) & 0.26 & 0.8 \\
\hline
\end{tabular}

Forecast data using the FTS-MC model. The forecasting results in 2019, with the actual amount of data as much as $30, l=25,659,839.67$, the current state is $A 1$ and the next state is an empty set
$(A-1 \rightarrow \emptyset)$ so based on Rule 1 in equation (4) the forecasting result is the middle from the fuzzy set $A 1$, that is $m 1$ is $18,043,107.83$. 


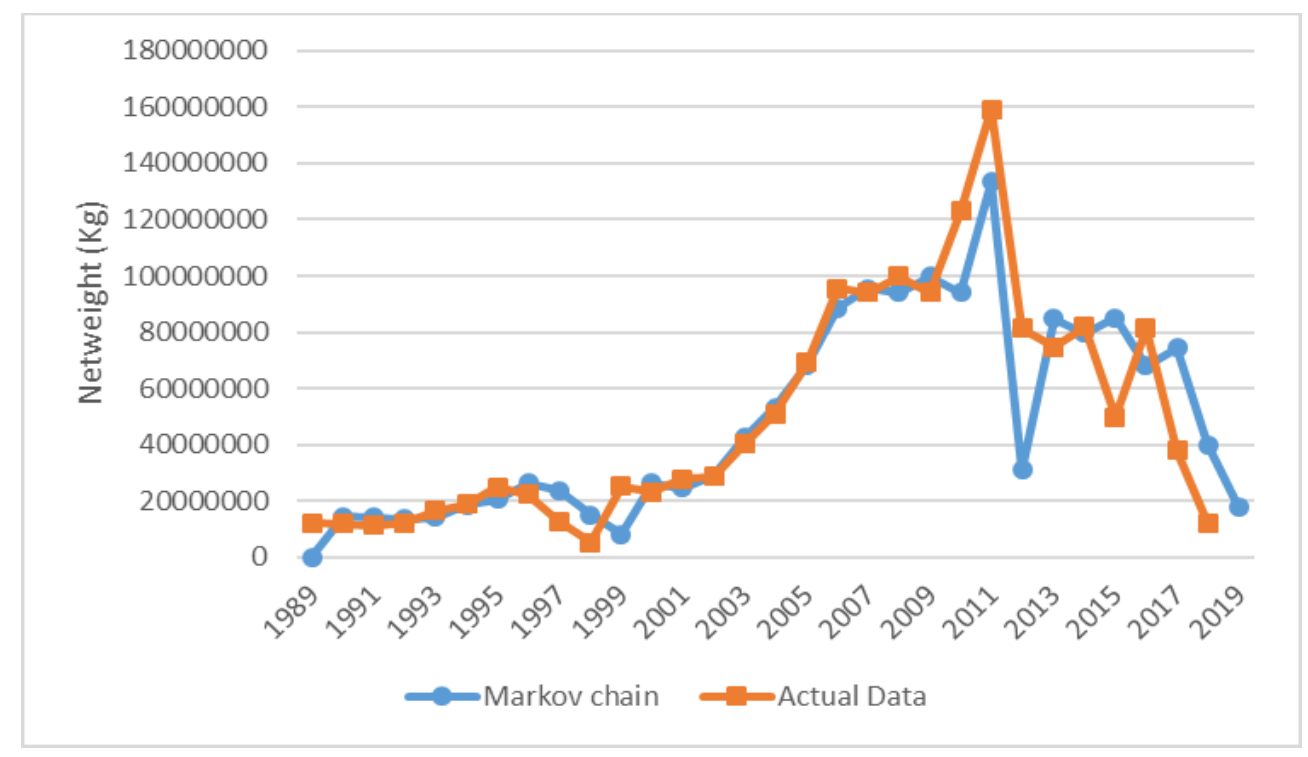

Figure 3. The Forecasting in Indonesia Seaweed Export

\section{CONCLUSION}

The Forecasted result with the Fuzzy Time SeriesMarkov Chain model follows the pattern of actual data. Forecasted with Fuzzy Time Series Markov Chain is better than without Markov Chain, Both the enrollment forecasting and the analytical exchange rate forecasting confirm the potential benefits of the new approach in terms of the proposed model. Most importantly, the illustrated experiments were archived with a very small MAPE. If the Markov fuzzy time series chain model meets expectations, then this approach will be an important tool in forecasting (Tsaur, 2012).

Comparison of forecasting the number of Indonesian seaweed exports using the Fuzzy Time series and Fuzzy Time Series Markov Chain, from the two models it is known that better results are in the fuzzy time series Markov chain. The level of accuracy of the two models can be seen from each of the MAPE and MSE values. It is known that the value of MAPE and MSE Fuzzy Time Series Markov Chain tends to be smaller than the Fuzzy Time Series. This means that the level of accuracy is higher than the actual data. The results of forecasting Indonesian seaweed exports in 2019 using the FTS-MC model is decreased $45 \%$ compared to 2018 .

\section{REFERENCES}

Arumugam, P., V.J.I.J.o.E.T. Anithakumari, and T.-V. Issue8-August. 2013. Fuzzy Time Series Method for Forecasting Taiwan Export Data.

Assosiation Seaweed Indonesia. 2019. (online) http://www.arli.or.id/ access on 2 April 2019

Brockwell, P.J., R.A. Davis, and M.V. Calder. 2002. Introduction to time series and forecasting. Vol. 2: Springer.

Budiharto, W. and D.J.Y.A. Suhartono. 2014. ARTIFICIAL INTELLIGENCE konsep dan penerapannya.

Central Statistics Agency, Buletin Statistik Perdagangan Luar Negeri Ekspor Menurut Kelompok Komoditi dan Negara, Januari 2019. [Export Foreign Trade Statistics Bulletin According to Commodity and Country Groups, January 2019].Badan Pusat statistik Republik Indonesia.[Central Statistics Agency of the Republic of Indonesia]. Jakarta.[Bahasa Indonesia].

Hikmah, H.J.J.k.s.e.k.d.p., Strategi Pengembangan Industri Pengolahan Komoditas Rumput Laut e. Cotonii untuk Peningkatan Nilai Tambah Di Sentra Kawasan Industrialisasi. 2015. 5(1): p. 27-36.

Ministry Marine and Fisheries. 2019. (online) https://kkp.go.id/djpdspkp/artikel/7947kinerja-ekspor-produk-perikanan-indonesiatahun-2018 access on 2 April 2019 
Song, Q., B.S.J.F.s. Chissom, and systems, Forecasting enrollments with fuzzy time series-part I. 1993. 54(1): p. 1-9.

Trade Map. 2019 (online)

https://www.trademap.org/Index.aspx access on 2 April 2019.

Tsaur, R.-C.J.I.j.o.i.c., information and control, $A$ fuzzy time series-Markov chain model with an application to forecast the exchange rate between the Taiwan and US dollar. 2012. 8(7): p. 4931-4942.
Uzun, B. and E.J.P.c.s. Kiral, Application of Markov chains-fuzzy states to gold price. 2017. 120: p. 365-371.

Xihao, S. dan Yimin, L. 2008. Average-Based Fuzzy Time Series Models For Forecasting Shanghai Compound Index. World journal of modelling and simulation, 4(2): 104-111.

Zadeh, L.A., G.J. Klir, and B. Yuan, Fuzzy sets, fuzzy logic, and fuzzy systems: selected papers. Vol. 6. 1996: World Scientific. 